\title{
Mobilizing Consensus on Facebook: Networked Framing of the U.S. Gun- Control Movement on Facebook
}

\author{
K. Hazel Kwon \\ Arizona State University \\ khkwon@asu.edu
}

\author{
Chun Shao \\ Arizona State University \\ cshao9@asu.edushawn
}

\author{
Shawn Walker \\ Arizona State University \\ shawn.w@asu.edu
}

\author{
Tanush Vinay \\ Arizona State University \\ tvinay@asu.edu.
}

\begin{abstract}
This study draws on networked framing and intermedia network agenda-setting theories to examine how different informational actors have framed the March for Our Lives gun control movement in 2018. This study uses the Social Science One Facebook URLs share dataset to compare network-agenda setting of different media types including offline news media, partisan sites, nonpartisan sites, advocacy/activism organizations, and social media/aggregate services. Results suggest that news media's framing was the richest and most dynamic, suggesting their important roles in setting the gun issue as a salient public agenda. Meanwhile, emerging media expanded the scope of framing by covering race, gender, and equity issues into gun politics. The movement/activist organizational actors showed the least similarity to other media types, inviting further questions on the role of movement/activist actors in shaping public attention and agendas in the process.
\end{abstract}

\section{Introduction}

Social movements and protests are a vital part of participatory democracy, driving meaningful social change across the globe. The mainstreaming of protest culture in recent decades is partly attributed to digital networks due to their cost-effectiveness, speed of information transmission, and the decentralized mobilization of sympathizers and participants [1].

Digital networks contribute to the shifting dynamics of three structural conditions underlying a successful collective action: framing structures (e.g., collective identities and slogans as framed in protest messages), resource mobilization structures (e.g., activism/movement organizational workings for recruitment and resource allocations), and opportunity structures (e.g., socio-political structural factors that restrain or promote participation) [2]. These three structural conditions work in tandem to fulfill two modes of mobilization: consensus mobilization, referring to spreading information and building morale conducive to participation; and action mobilization, referring to making people engage in tangible activities such as walkout, demonstration, petition, or donation [3]. It is widely agreed that digital networks catalyze both consensus and action mobilization by allowing activists to enhance their visibility and networking capacity, expand protest toolkits, and propagate protest slogans and symbols [1].

This study focuses on consensus mobilization, a prerequisite for action mobilization [4]. What social movement scholars call consensus mobilization resonates with "public issue salience" (and the salience of the issue's attributes) in media scholars' language [5]. News media attention has been an important mechanism to raise public issue salience [5]. Accordingly, analyses of consensus mobilization have referred to the media industry's information regimes such as newspaper subscriptions, availability of news stations, or frequency of news coverage [6,7]. In today's networked environment, informational actors that contribute to shaping public issue salience during social movement have become diversified beyond traditional mass media [8].

This study attempts to understand how consensus mobilization unveils in this diversified media landscape. Theoretically, this study borrows the lenses of "networked framing" $[9,10]$ and "intermedia network agenda-setting" $[8,11]$, both of which underscore the interplay between traditional and emergent informational actors in constructing public understanding of the political reality. Methodologically, we leverage Facebook URL share data, which provides granular attention metrics about both traditional media and alternative informational actors. These metrics help understand audience reach at the story and concept level. We employ text network analysis of Facebook dataset, while interpretively discussing the results.

The study's empirical context is a recent guncontrol movement in the U.S., called the March for Our Lives (MFOL) in 2018. The movement reached its momentum in the aftermath of the deadly shooting event at Marjory Stoneman Douglas High School in Parkland, Florida. The movement became known by its social media hashtags \#NeverAgain and \#EnoughisEnough 
and the large-scale offline protests which called for stricter gun regulations. While the hashtags existed before MOFL, they quickly became synonymous with the movement and immediately went viral. MFOL was a nationwide (and to some extent, global) demonstration which staged one of the largest protests in American history [12]. This study analyzes the titles and blurbs of 11 months of URLs shared on Facebook starting in February, 14, 2018, when the Parkland school shooting had occurred, through the rest of 2018.

\section{Consensus mobilization in digital age}

Consensus mobilization depends heavily on public and media relations. While the ability of social movement organizations to fundraise and manage resources has been an integral asset to mobilize consensus as well as actions, opportunity structures and framing structures play a particularly important role in understanding consensus mobilization [13].

\subsection{Opportunity structure for mobilization}

Opportunity structures are broadly defined as "consistent - but not necessarily formal or permanentdimensions of the political struggle that encourage people to engage in contentious politics" [14]. The elements of opportunity structures are categorized into two types: "opportunities for influence (OI)" and "opportunities for mobilization (OM)" [15]. OI refers to political conditions conducive for activists to exert actual influence on the existing political institutional workings, for example openness of political elites, tolerance or repressive capacity of the government, recent policy changes, and international alliances [15].

Meanwhile, OM refers to socio-cultural conditions that influence public perceptions of the movement's chance for success [16]. Whereas resource mobilization structures pertain with resource allocation endogenous within and across activists' social networks and organizations $[17,18]$, OM is tied to the general public's attention as an external asset that affects the outcome of the mobilization.

Public attention is so essential to the success of social movements that activists put considerable effort into issuing awareness campaigns and making them salient in media coverage [13]. As Rucht pointed out, "for social movements that typically lack financial resources and direct access to political decision-makers, getting public attention and support is a major mechanism through which social and political change may be affected" [19, p. 200]. Stated differently, consensus mobilization depends on a communication infrastructure that channels public attention. Traditional examples are newspaper subscriptions [6,20], availability of local television [20], radio stations [7], and interpersonal social contacts $[21,22,23]$.

In the digital environment, protest-related posting activities in Twitter and Facebook have served as an indicator of public attention, showing that networked informational flow forecasted the development of onsite mobilization [24]. That said, they did not disentangle protesters' endogenous communication activities with other types of information. Meanwhile, another study [9] examined the Facebook friendship network as a latent communication channel through which protest information could spread during the Arab Spring. However, their study relied on the friendship network data, and thus failed to gauge the extent of actual information flow relevant to the protest. This study complements prior efforts by examining the issuerelevant information originating from various types of sources in addition to protester communities.

\subsection{Networked framing}

Collective action framing addresses the ways in which social movement narratives are constructed. In a traditional social movement setting, collective action framing is largely controlled by activist groups that have financial and human resources to disseminate their unified slogans and symbols [25].

Meanwhile, the digital environment adds in the ever-expanding role of online publics [26,27] who organically share a variety of information and conversations that intermixes news coverage, activist messages, memes, catchphrases, emotions, and both pro- and counter-protest opinions [27,28]. This is known as the process of "networked framing."

Networked framing refers to the construction of multifaceted narratives of a social movement including both supportive and opposing narratives. The process not only involves activist/advocacy agents but also alternative informational actors in digital spaces, who take part in creating, processing and distributing information. Alternative informational actors may widely range across individuals, small groups, nontraditional media sites, platform owners, noninstitutional and institutional organizations, as well as general public $[9,10]$. For example, studies of Twitter discourses have reaffirmed the role of ordinary, and even marginalized, users' storytelling in shaping the outlooks of protest agendas [29]. Sometimes, networked framing is a contested process that presents fragmented frames between protest cores (i.e., seasoned activists), spectator peripherals (i.e., ordinary public members 
who express opinions online), and traditional influentials [30].

During networked framing, ideas and messages pursued by the social movement no longer belong to the protest/activist organizations, but emerge and evolve as part of a larger digital information ecosystem. In other words, networked framing transcends collective action frames and serves as a vital process to mobilize public consensus.

\subsection{Intermedia network agenda-setting}

Related to networked framing, agenda-setting theory is one of the most established and classical media theories that explain how media coverage shapes the public's perception of political reality. While the original focus of agenda-setting theory has been on the effect of journalist coverage on setting public agendas in terms of what to think about and how to evaluate them [5], the theory has been advanced to focus on and explain various aspects of media ecosystem.

Especially, two theoretical advancements echo the process of networked framing. First, intermedia agenda-setting contends that media not only influence audiences' agendas but also those of other media entities. For example, studies have demonstrated the influence of elite newsrooms on smaller news outlets' agendas; newspapers on television broadcast; political advertising on television and press news [31]. In digital spaces, the interdependence between traditional news media and emergent media attention to public/political issues have been prominent [e.g., 8,31,32].

While most of intermedia agenda-setting research examined the volume of issue attention (i.e., how frequently an issue was covered or mentioned), incorporating another advancement in this theoretical domain -network agenda-setting model -into an intermedia context has proven useful to understand how issues are interrelated or what attributes of an issue are associated in media narratives and, more importantly, how such conceptual bundles are propagated across different media entities to create dynamic news narratives in a complex media ecosystem.

Most recently, studies have demonstrated that fake news entities' agenda-setting effect on carrying over into mainstream media (especially partisan one like Fox News) was stronger than fact-checking sites, [33]. Another related study has shown that, during the 2016 election, the intermedia flow of misinformation was particularly prominent for Trump but not for Clinton [34].

\subsection{Summary and research questions}

The notions of networked framing and intermedia network agenda-setting help conceptualize consensus mobilization in today's networked social movement. Networked framing perspective explains why the interplay among different informational actors has become vital part of consensus mobilization in network societies. Moreover, intermedia network agenda-setting model offers an analytic framework to systematically examine this interplay, with the particular focus on various types of media actors.

This study's empirical context is gun violence and gun-control movement in the U.S. centered around the case of the 2018 March for Our Lives. Based on the networked framing perspective and intermedia network agenda-setting approach, we analyze URLs that were publicly shared in Facebook to address the following research questions.

RQ1: How has the salience of issue attributes of gun control movement evolved over time?

RQ2: How have different informational actors framed the gun control movement?

RQ3: How different or similar are the gun control movement frames across informational actor types?

\section{3. 'March for Our Lives' in context: Gun politics in America}

'March for Our Lives (MFOL)' has become a common moniker for the 2018 gun control movement. MFOL emerged after a mass shooting incident at Marjory Stoneman Douglas High School (MSD) in Parkland, Florida on February 14, 2018. The movement emerged in response to the shooting via student activists' collective effort to use the hashtags \#NeverAgain and \#EnoughisEnough; host multiple town hall meetings, including one sponsored by a national media (CNN); and organize nationwide protests like national walkouts and March for Our Lives (MFOL).

MFOL demonstration was a keynote offline event that became a symbol of the combined online and offline movement. It was a series of student-led rallies to advocate for stricter gun control in the United States as well as the proactive political engagement of young adults. The demonstrations took place across more than 800 cities in the U.S. and around the world, reportedly becoming "one of the largest expressions of popular opposition in the modern era" [35]. The march in 
Washington D.C.- - the protest's main hub — set a record for "the largest single-day protest in the history of the nation's capital" [35].

While these events were the apparent components of the 2018 movement, the gun control movement is in fact deeply embedded in social, historical, and policy structures surrounding the nation's gun politics. Despite being one of the most persistent public agendas, few large-scale gun-control related protests or movements occurred prior to MFOL. Perhaps the most recognizable protest before MFOL was the Million Mom March in 2000, held in response to high-profile shooting incidents. While this event quickly ballooned into 70 cities around the U.S. and drew broad media attention, the political agendas were unclear, resulting in little long-term impact. The majority of participants joined the march simply "out of the concerns for the safety of [their own] child," and the march was devoid of political messaging [36]. While the first Million Mom March turned out hundreds of thousands of protesters, its second iteration mobilized only 200 protesters [36].

One reason for the lack of a successful movement surrounding gun politics may be attributed to the divisive nature of this issue. Gun policies hinge on a myriad of conflicting views and issues based on differing interpretations of the Second Amendment. Legal perspectives have been mixed as well. On the one hand, the United States v. Warren decision reflects that the Second Amendment falls to active members of the country's militia and thus the Second Amendment should be a "collective" or "state's" right, holding "no barrier to gun prohibition" [37]. On the other hand, court decisions in the late 2000s suggest that individuals do hold the right to bear arms [38].

Currently, much of the gun control debate has pertained to what types of guns should be restricted or outright banned, featuring, for example, disagreements over handgun restrictions and whether semi-automatic weapons should be banned. While semi-automatic weapons moved to the forefront of national issues following the 1989 schoolyard shooting in Stockton, California [37], banning certain types of weapons remains a contentious issue and has been one of main agendas for MFOL. To summarize, like other social movements, MFLO has risen from an intricate sociopolitical history.

\footnotetext{
1 The database developers did not indicate the national origin of each URL. Instead, they consider a URL belonging to a country where it was shared the most.
}

\section{Research designs}

\subsection{Data preparation}

4.2.1. Data collection. We leveraged Facebook's privacy-protected full URL data set [39] that was accessible as part of Facebook's collaboration with Social Science One. Our data was derived from their database of URLs and attributes shared by at least 100 times with "public" privacy settings. This allowed us to examine URLs that have garnered some level of public attention on Facebook. More importantly, this dataset is advantageous for capturing all headlines and blurbs of historic URLs including those that do no longer exist.

We used a multi-step process, described below, to filter, clean, and refine data from the URL shares database. First, we retrieved URLs relevant to MFOL using a created list of keywords which were compiled through a snowball sample of news headlines $(N=4468)$ via a search in Nexis Uni. The final keyword list contained 55 words or phrases reflective of gun violence, gun politics, and the MFOL movement itself (e.g., 'neveragain,' 'enough is enough,' 'crisis actor', 'gun AND activist', 'gun safety', 'nra', 'town hall AND gun', 'national walkout', 'vigil AND school', 'school AND shooting'). The time window for data collection was from February 14, 2018, the day of the shooting event, to the end of 2018.

Next, we reviewed 5\% random samples of URLs' headlines and blurbs stratified by week to further refine the search parameters. For example, the review process informed us that searching with the single keyword 'protest' ended up retrieving URLs about every kind of protest that occurred across the globe in 2018, beyond the context of this study. We thus decided to retrieve the URLs using this single-keywords only in February and March when the MFOL movement was at its peak. Furthermore, we confined the geographical parameter to the U.S. ${ }^{1}$ To summarize, after filtering out false positive URLs, the final dataset consisted of 32,141 unique URLs from 3,332 different parent domains. Together, these URLs were shared by more than 44 million users. Importantly, the size of sharing users is an estimate that accounts for the noise added to the database as a part of privacy-protection procedure, called "differential privacy" technique [39]. To derive the value, we used the SVINFER python package to estimate each URL's number of users who shared it, and then combined the estimates. 
4.2.2. Text mining. Each URL's headline and blurb combined into a 'document'. The NLTK python package was used to standardize documents including lowercasing, removing stop words, punctuation, and lemmatization. We then reviewed lists of bigrams and trigrams and their frequency distributions, concatenating conceptually similar trigrams occurring more than 500 times and bigrams occurring more than 200 times.

4.2.3. Informational actor types. To compare different informational actors, we manually annotated the parent domain of each of 3,332 URLs into one of the five categories. The five categories were defined based on prior works [11, 40], with the inter-coder reliability $\mathrm{Kappa}=.811$.

(1) Offline-based news media: websites of traditional press and broadcast media outlets that begun its operation as offline media entities (e.g., cnn.com, abcnews.go.com, nytimes.com) or websites affiliated with media conglomerates such as USAToday, Scripps, McClatchy, and Sinclair (e.g., columbiatribune.com)

(2) Partisan sites: partisan and hyper-partisan sites that exist only online, either run as an organization or as a personal/small group site. We also included adversary state-run media that sometimes spread highly divisive contents (e.g., huffpost.com, thegatewaypundit.com, redstate.com, rt.com).

(3) Nonpartisan sites: online-only nonpartisan websites of which primary purpose is to create and provide information not immediately echoing partisan ideology (e.g., cnet.com, lifehacker.com)

(4) Advocacy-related organizations: websites run by organizations or groups that aim for advocacy, activism, movement, social change, or other political participation interests (e.g., nratv.org, change.org)

(5) Social media/aggregate services: social media, news aggregator or portal sites whose main function is to aggregate and deliver content created by other sites or users (e.g., youtube.com, yahoo.com, reddit.com)

(6) Others: un-codifiable by the above categories (e.g., fbi.gov, amazon.com) or inaccessible broken links ${ }^{2}$ (e.g., americantouch.us). This category was excluded from further analysis.

4.2.4. Text networks. We built five networks, representing each of the informational actor types. A network object was composed of two sets of data: words as nodes and co-occurrences of pairs of words as edges. For consistency, we applied the same node-list to all network objects.

\footnotetext{
${ }^{2}$ We manually investigated to trace the identity of a broken link as much as possible. For example, some websites did not operate any
}

A node-list represented all actor types in a balanced way. Specifically, within each actor type, we computed the document frequency of every word, then selected the top 200 words. Many of these words overlapped across the informational actor types. After de-duplication and removal of generic words (e.g., 'go', 'since', 'let', 'say'), days and numbers (e.g., monday, three, year), and words that were hard to interpret (e.g., de, la, el); the final combined node-list contained 255 words. We then created a weighted edge-list for each informational actor type. The edge weight E $i j$ was defined as the number of documents that contained both words $i$ and $j$ (cooccurrence).

Most words co-occurred at least once across all five networks, resulting in an unusually high density rate $(>$ 0.9 , based on an unweighted graph). After manually reviewing the raw data, we learned that some blurbs included extremely long text that aggregated numerous headlines, creating an edge for almost every pair of nodes. Existence of these random edges would hinder interpretation of the semantic relationships in a meaningful way. Accordingly, we regenerated the graphs with edges whose weights were 50 or higher, meaning that a pair of words should appear together at least in 50 documents (headline + blurb) to be included as an edge in the network.

\section{Results}

\subsection{Descriptive analysis}

Table 1 summarizes the number of unique parent domains, URLs, and words belonging to each informational actor type. The traditional media category included the highest number of unique domains $(\mathrm{N}=1,083)$ and accounted for the largest number of URLs spread in Facebook $(\mathrm{N}=12,042)$. Partisan sites $(\mathrm{N}=262)$ and social media/aggregate services $(\mathrm{N}=60)$ contained fewer domains yet their URLs were widely shared $(\mathrm{N}=6,392 ; \mathrm{N}=4,162)$. Also, although not widely shared, there were many domains $(\mathrm{N}=336)$ that were inaccessible (Other).

Table 1. Number of parent domains and URLs in each informational source type.

\begin{tabular}{|l|l|l|l|}
\hline Sources & Parent domains & URLs & Words \\
\hline trd & 1,083 & 12,042 & 25,807 \\
\hline par & 292 & 6,394 & 20,467 \\
\hline
\end{tabular}

more -thus broken link - but continued to provide their content via a third-party platform like Facebook page. The un-codifiable category was applied only when our manual investigation led nowhere. 


\begin{tabular}{|l|l|l|l|}
\hline npar & 960 & 5,724 & 22,959 \\
\hline adv & 601 & 2,558 & 14,944 \\
\hline sm/a & 60 & 4,162 & 18,908 \\
\hline other & 336 & 1,262 & 7,524 \\
\hline Total N & 3,332 & 32,141 & 54,212 \\
\hline
\end{tabular}

Note: trad = traditional media; par = partisan sites; $\mathrm{npar}$ =nonpartisan sites; $\mathrm{adv}=$ advocacy-related organization; sm/a = social media/aggregate services.

While we did not conduct a systematic analysis with the 'Other' category, messages contained in URLs originating from this category were often highly conspiratorial and polarizing. For instance, a notorious conspiracy theory that student activists were crisis actors was mentioned in several broken URLs, such as "The arrogant left doesn't even bother to tell their crisis actors to stay off $T V$..." from the inaccessible site rickwells.us. Instead, the crisis actor-conspiracy theory mentioned in other source types often reputed the claim, for example, "A Florida state representative fired one of his aides on Tuesday after the man sent an email to a reporter, claiming students who spoke on TV about the Parkland school massacre were crisis actors" from nypost.com.

\subsection{Overtime trend of selected words}

Figure 1 visualizes the trends of public attention (RQ1) based on the weekly proportion of a selected keyword's document frequency of three representative topics. The Figure 1 topics include: (1) the triggering event (Parkland shooting), (2) the MFOL movement, and (3) general gun politics. We selected keywords:

(1) 'parkland_shoot,' 'school_shoot,' 'victim,' and 'nikolas_cruz' (the perpetrator) to represent the trigger event;

(2) 'david_hogg' (a leading activist), 'enough_enough' (slogan), 'march_life' (MFOL), and 'protest' to represent the MFOL movement itself; and

(3) 'congress', 'firearm', 'gun_law', 'gun_safety', and 'national_rifle_association' to represent gun politics.

The overtime trends show that public attention shifted from the triggering issue (1-3 weeks) to the MFOL movement (4-8 weeks), which coincided with the peak time of offline protest. That said, the movement slogan "enough_enough" had a steadfast presence throughout the year, alluding to activists' struggle to maintain the movement's salience. Meanwhile, gun politics-related keywords continued to present, suggesting that the movement was successful in sustaining the gun regulation issue as an enduring public agenda.

\section{Figure 1. Weekly Proportions of Document Frequency for Selected Keywords}

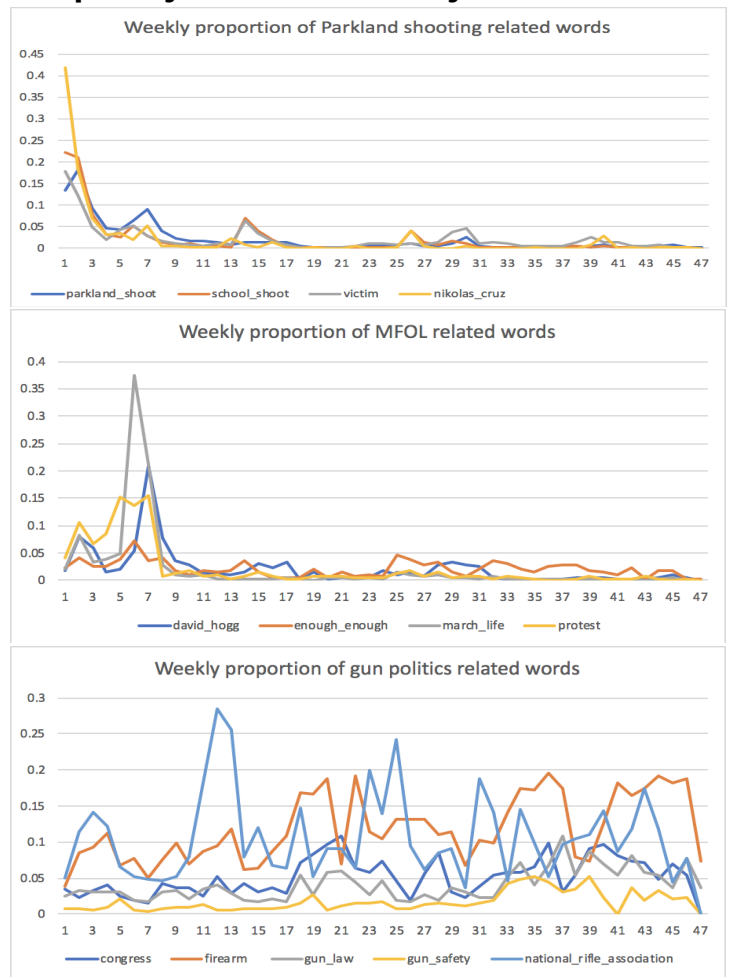

\subsection{Text network analysis}

To understand networked framing by different information sources (RQ2), we compared text network structures for each information source type. The number of nodes (words) included in text network analysis was 255. Table 2 compares the network structural characteristics among the five graphs. The text network structures for each information source type are visualized in Figure 2.

5.3.1. Traditional media. The traditional media category accounted for the largest portion of edges, implying that it offered the richest narrative of the issue. Traditional media reported considerable details about the triggering event by focusing on locations (e.g., Florida, parkland, school) and stakeholders (e.g., police, victim, teacher), while also expanding the scope of attention toward other shooting events and politician responses toward gun violence (e.g., trump, official, republican). For instance, the headline of a Tampa Bay Times article stated: "Moments after the shooting at a Broward County high school on Wednesday, President Donald Trump offered Florida any federal assistance 
needed, the White House said." Similarly, an article from the Washington Post reported: "The president framed the mass shooting...as indicative of a mentalhealth issue, rather than a gun-control problem." Many URLs originating from traditional media followed a journalistic writing style based on factual reporting and delivering the response of political elites and notable activists to the accident and the movement.

Table 2. Network structure characteristics

\begin{tabular}{|l|l|l|l|l|l|}
\hline & trd & par & npar & adv & sm/a \\
\hline Node & 255 & 255 & 255 & 255 & 255 \\
\hline Edge & 829 & 242 & 238 & 83 & 31 \\
\hline $\begin{array}{l}\text { Edge } \\
\text { weight }\end{array}$ & 86.30 & 70.17 & 66.08 & 86.161 & 64.30 \\
\hline Degree & 17.09 & 4.70 & 4.18 & 0.55 & 1.50 \\
\hline $\begin{array}{l}\text { Weighted } \\
\text { degree }\end{array}$ & 1475.03 & 329.73 & 275.90 & 47.27 & 96.16 \\
\hline Density & 0.18 & 0.05 & 0.04 & 0.01 & 0.01 \\
\hline
\end{tabular}

Note: The values are based on filtered graphs with edge weight 50 and higher; trad = traditional media; par = partisan sites; npar $=$ nonpartisan sites; $a d v=$ advocacy-related organization; $\mathrm{sm} / \mathrm{a}=$ social media/aggregate services.

5.3.2. Partisan sites. Partisan sites centered around the contestation between democrats and republicans. For instance, a left-wing source (bipartisanreports.com) stated: "Every time there is a mass shooting involving students in America, we collectively hope that this time will be different. We hope that something will break the usual cycle of grief, anger, condolences, and inaction by Republican politicians. When the attention fades, Republicans take the opportunity...." In contrast, a rightwing source (westernjournal.com) stated, "In the wake of every major mass shooting, the Democrats demand gun control legislation be the dominant media narrative. They don't mention what that legislation would actually entail, mostly because what they propose would either a) not work, b) violate the Constitution or c) both."

Furthermore, partisan sites paid closer attention to gun-policy issues than the shooting incident itself (e.g., NRA, gun_control, call, gun violence, right) with the then-president Trump at the center of the discussion. Also, David Hogg, a survivor of the MSD shooting who became an iconic activist, was frequently mentioned by partisan sites. His name was linked with words such as "activist, twitter, NRA," which emphasized his role in the movement. For example, toprepublicanews.com reported that "Immediately after the Florida school shooting, the mainstream media was lining up to interview student survivor David Hogg, who condemned President Donald Trump and demanded gun control." Many URLs originating from the partisan sites touched on the legitimacy of Hogg as an activist. For instance, "the ex-FBI agent father of one of the survivors of the high school shooting in Parkland, Florida, lashed out at conspiracy theorists who claim his son was not witness to the massacre but a crisis actor who shows up at shootings to draw media attention (rawstory.com)."; "Several posts about David Hogg that have surfaced in the wake of the shooting are being methodically purged from accounts that offer an alternative or critique of those interviews rather than the mainstream news narrative (sonsoflibertymedia.com)."
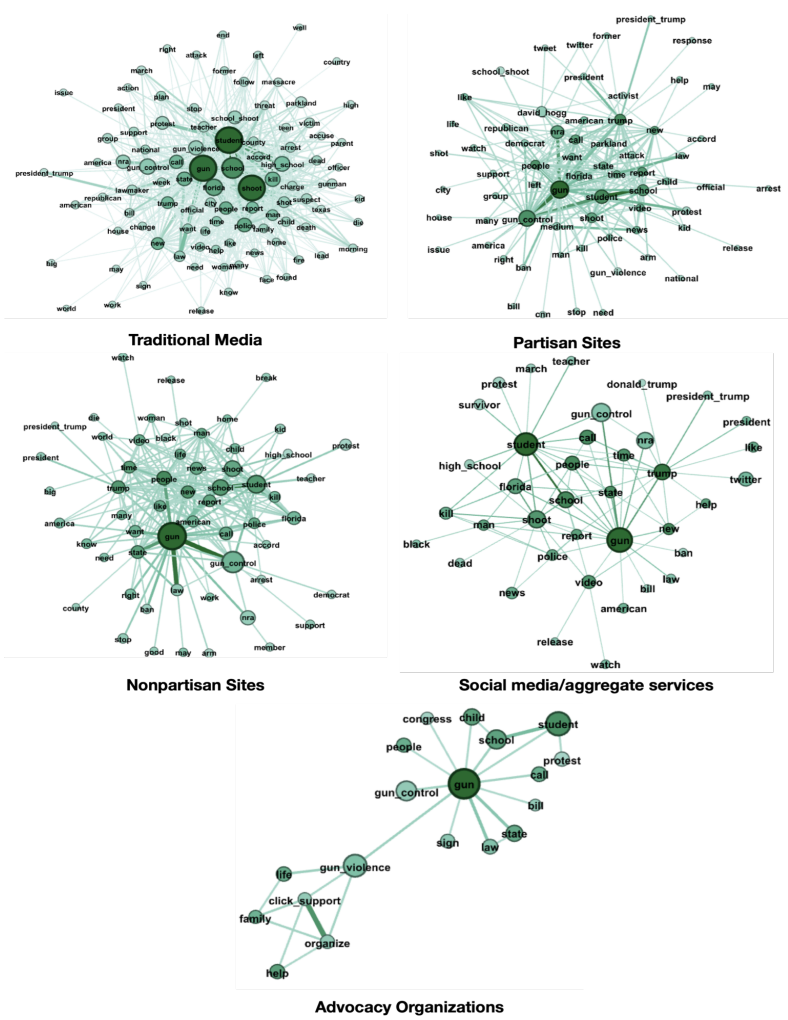

Figure 2. Text network by informational source type. Node size adjusted by document frequency; color gradation adjusted by weighted degree centrality.

5.3.3. Non-partisan sites. Topics discussed in nonpartisan sites showed a similarity to partisan sites, although non-partisan sites touched upon aspects of race, diversity, and equity issues more frequently, situating gun politics in broader socio-cultural contexts. For instance: "Florida school shooter was a raving racist who hated black people, interracial coupling, Instagram group chat shows (atlantablackstar.com)." "Children of color already face violent discipline in schools. Arming teachers will get them killed (theintercept.com)." 
5.3.4. Social media or aggregate Services. Not surprisingly, this category drew sources from other types of media, resulting in resemblance to other categories. For example, prominent words in this network such as "student, Florida, people, trump, state, gun, report" occurred likewise prominently in other networks. This category drew information directly from other sources, for example, "NRA national spokesperson Dana Loesch tells ABC News' George Stephanopoulos the focus in the aftermath of the Parkland shooting should be local and FBI authorities..." (from ABC News Youtube Channel). Similarly, "Broward County sheriff says he won't resign amid controversy over Parkland school shooting" (from Fox News Youtube Channel).

Notably, there were quite a few rumor-related headlines/blurbs in this category. For instance, a Youtube channel reported that "David Hogg, who is rumored to be the son of a member of the FBI, seems to be coached and given lines in his interview with CNN." Also, Yahoo News reported, "Yet another conspiracy theory about student activist David Hogg circulated on social media on Monday and Tuesday. Boosted by popular right-wing blogs, the stories falsely allege that the Marjory Stoneman Douglas High School student wasn't on campus when the Parkland, Florida, shooting broke out."

5.3.5. Advocacy-related organizations. This category heavily centered around gun regulation, reflecting both pro- and anti-gun control viewpoints. Prominent words such as "congress, gun_control, bill, state, law, sign" reflected that organizations called either for protecting the Second Amendment or enhancing gun control. For instance, the National Association for Gun Rights (nagr.org) posted that "After the shooting in Parkland, $F L$, anti-gunners are on the warpath to send our Second Amendment rights through a shredder!" In contrast, an activist organization posted that "the Florida Senate has voted to support a number of new gun control measures following the massacre at Marjory Stoneman Douglas High School in Parkland, Florida (democracynow.org)." That is, both perspectives existed in the dataset.

Efforts to mobilize support and help for a certain group (e.g., student, faculty, schools) were salient in this category. For example, a MSD alumni group raised an online fundraising campaign with this blurb: "Mobilizing MSD Alumni is a group of more than 11,500 alumni of Marjory Stoneman Douglas High School. We were formed in the aftermath of the mass shooting at MSD on February 14th, 2018, with the intention of supporting current students and faculty, as well as to help advocate for change."

\subsection{Text network correlations}

Three different correlation metrics were compared to understand how similar --or different --the five text networks are (RQ3), including rank correlations of degree centrality, rank correlations of document frequency, and quadratic assignment procedure (QAP)based network correlations. The results (Table 3) show that advocacy-related organizations were least correlated with the rest of graphs, implying the distinctive role that this category has in the process of consensus mobilization.

Meanwhile, partisan and non-partisan networks showed the highest correlations across all three metrics, implying that their narrative patterns were more similar to each other compared to other source types. The text network of social media and aggregate services showed high correlation with traditional media, partisan, and nonpartisan sites based on the document frequency, and its correlation with partisan and nonpartisan sites still remained strong when tested by degree centrality and QAP. This result is not a surprise given that social media/aggregate services mostly deliver information from other source types rather than creating their own.

Table 3. Correlations among Informational Source Type Networks

\begin{tabular}{|c|c|c|c|c|}
\hline \multicolumn{5}{|c|}{ Rank correlations: Document frequency } \\
\hline & 1 & 2 & 3 & 4 \\
\hline \multicolumn{5}{|l|}{ 1.Traditional } \\
\hline 2. Partisan & \multicolumn{4}{|l|}{0.603} \\
\hline 3. Nonpartisan & 0.657 & \multicolumn{3}{|l|}{0.781} \\
\hline 4. Social/aggregate & 0.740 & \multicolumn{3}{|c|}{0.7740 .765} \\
\hline 5. Advocacy & 0.415 & 0.404 & 0.554 & 0.430 \\
\hline \multicolumn{5}{|c|}{ Rank correlations: Degree centrality } \\
\hline & 1 & 2 & 3 & 4 \\
\hline \multicolumn{5}{|l|}{ 1.Traditional } \\
\hline 2. Partisan & \multicolumn{4}{|l|}{0.481} \\
\hline 3. Nonpartisan & 0.490 & \multicolumn{3}{|l|}{0.674} \\
\hline 4. Social/aggregate & 0.420 & \multicolumn{3}{|c|}{0.5750 .567} \\
\hline 5. Advocacy & 0.080 & 0.093 & 0.162 & 0.165 \\
\hline \multicolumn{5}{|c|}{ QAP-based network correlation } \\
\hline & 1 & 2 & 3 & 4 \\
\hline 1.Traditional & \multirow{2}{*}{\multicolumn{4}{|c|}{0.397}} \\
\hline 2. Partisan & & & & \\
\hline
\end{tabular}




\begin{tabular}{|l|llll|}
\hline 3. Nonpartisan & 0.412 & 0.571 & & \\
\hline 4. Social/aggregate & 0.261 & 0.472 & 0.488 & \\
\hline 5. Advocacy & 0.073 & 0.110 & 0.107 & 0.430 \\
\hline
\end{tabular}

Note: Rank correlations based on Spearman's Rho test; all significant at $p<.001$

\section{Conclusion and discussions}

This paper explored consensus mobilization of the U.S. gun control movement on Facebook during MFOL. Becoming an essential part of the process of consensus mobilization in digital age, networked framing involves not just activists and sympathizers but also alternative informational actors who have a say -both supportive and opponent -about the issue at hand. This study took advantage of the researchers' access to the entire Facebook URLs share database and analyzed the data using the intermedia network agenda-setting model framework. The comprehensive access to this dataset allowed us to go beyond just studying protester communities, and enabled a comparative analysis of intermedia flow of issue attributes used to frame gun violence, gun politics, and the 2018 MFOL movement.

This project contributes to the literature by intersecting social movement's consensus mobilization and intermedia network agenda-setting. The findings demonstrate the complex framing of gun control movement in today's hybrid media environment. Based on the findings, we offer a few insights.

First, traditional media has still been a central framing machine reassuring the importance of news coverage in consensus mobilization. In our study, offline-based news media category showed the most dynamic movement narratives. By reporting the trigger event closely, traditional media set the 'tone' of the nation, which was helpful in creating opportunity structures for the movement. Second, the narratives of partisan sites reflected the political battle over "opportunities for influence" [15]. Meanwhile, nonpartisan sites' narratives embraced race, gender, and equity issues. That is, nonpartisan information sources connected MFOL to existing identity politics and power struggles. This way of framing helped the movement organizers expand their "opportunities for mobilization" [15]. by broadening their sympathizer bases. Lastly, advocacy/activism organizations and groups seemed to play a unique role in networked framing. They were the most informative in terms of gun regulation agendas and mindful to spillover consensus into actions. That said, the correlation between them and other media entities also alludes a possibility of failing to incorporating activist agendas into more visible media narratives. More investigation would be helpful to interpret what it means that activists network agenda showed the lowest correlation among all types of informational actors.

\section{Limitations}

While this study comprehensively addresses the digital information ecosystem centered on Facebook, we examined networked framing without considering how extensively Facebook publics engaged with these frames. By considering the extent of user engagements, future research should be able to capture the degree of public attention more accurately as well as the level of virality in different frames and narratives. Also, while we took the intermedia network agenda-setting framework, we did not test temporal agenda flows from one media type to another. Thus, our results address similarities yet not causality. Lastly, we used Facebook URL to focus on intermedia framing among various informational providers, other data source like Twitter would help expand the scope of investigation by including ordinary public users' conversations.

\section{Acknowledgements}

This project was supported by Social Science Research Council's Social Media and Democracy Research Grant; and National Foundation Science (Award 2027387).

\section{References}

[1] W.L. Bennett, and A. Segerberg. "The logic of connective action: Digital media and the personalization of contentious politics", Information, Communication \& Society, 2012, 15(5), pp.739-768.

[2] D. McAdam, "Social movement theory and the prospects for climate change activism in the United States." Annual Review of Political Science, 2017, 20, pp. 189-208.

[3] B. Klandermans. "Mobilization and participation: Socialpsychological expansions of resource mobilization theory", American Sociological Review, 1984, 49(5), pp. 583-600.

[4] K.H. Kwon, W.W. Xu, H. Wang, and J. Chon, "Spatiotemporal diffusion modeling of global mobilization in social media: The case of 2011 Egyptian revolution", International Journal of Communication, 2016, 10, pp. 73-97. [5] M. McCombs and S. Valenzuela, "Setting the Agenda: Mass Media and Public Opinion”, 2020, Cambridge: Polity.

[6] K. T. Andrews, and M. Biggs, "The dynamics of protest diffusion: Movement organizations, social networks, and news media in the 1960 sit-ins", American Sociological Review, 2006, 71(5), pp. 752-777.

[7] V.J. Roscigno, and W.F. Danaher, "Media and mobilization: The case of radio and southern textile worker insurgency, 1929 to 1934." American Sociological Review, 2001, 66 (1), pp. 21-48.

[8] R.W. Neuman, L. Guggenheim, S.M. Jang, and S.Y. Bae, "The dynamics of public attention: Agenda-setting theory 
meets big data", Journal of Communication, 2014, 64(2), pp. 193-214.

[9] K.H. Kwon, and J. Hemsley, "Cross-national proximity in online social network and protest diffusion: An event history analysis of Arab Spring", In Proceedings of the 50th Hawaii International Conference on System Sciences, 2017, pp. 21462155.

[10] S. Meraz, and Z. Papacharissi, "Networked gatekeeping and networked framing on\# Egypt", The International Journal of Press/Politics, 2013, 18(2), pp. 138-166.

[11] C.J. Vargo, and L. Guo, "Networks, big data, and intermedia agenda setting: An analysis of traditional, partisan, and emerging online US news", Journalism \& Mass Communication Quarterly, 2017, 94(4), pp.1031-1055.

[12] O. Laughland, and L. Beckett, "Parkland teachers faced an impossible choice: 'Do I hold the door open or close it?'”, March 2018, The Guardian.

[13] B. Edwards, and J.D. McCarthy, "Resources and social movement mobilization", In D. Snow, S.A. Soule, H. Kriesi (Eds.), The Blackwell companion to social movements, Malden, MA, Blackwell Publishing, 2004, pp. 116-152.

[14] Tarrow, S.G., Power in movement: Social movements and contentious politics, Cambridge University Press, New York, 2011.

[15] D. S. Meyer, "Protest and political opportunities", Annual Review of Sociology, 30, 2004, pp. 125-145.

[16] W. Gamson, and D. S. Meyer. "Framing Political Opportunity." In Comparative Perspectives on Social Movements: Political Opportunities, Mobilizing Structures, and Cultural Framings, edited by Doug McAdam, John McCarthy, and Mayer Zald, Cambridge University Press, 1996, pp. 275-290.

[17] V. Bekkers, H. Beunders, A. Edwards, and R. Moody, "New media, micromobilization, and political agenda setting: Crossover effects in political mobilization and media usage", The Information Society, 2003, 27(4), pp. 209-219.

[18] P. Hedström, R. Sandell, and C. Stern, "Mesolevel networks and the diffusion of social movements: The case of the Swedish Social Democratic Party", American Journal of Sociology, 2000, 106(1), pp. 145-172.

[19] D. Rucht, Movement allies, adversaries, and third parties. In D.A. Snow, S.A. Soule and H. Kriesi, (eds). The Blackwell Companion to Social Movements. Malden, MA: Blackwell, pp. 197-216.

[20] D. J. Myers, "Racial rioting in the 1960s: An event history analysis of local conditions", American Sociological Review, 1997, 62(1), pp. 94-112.

[21] R.V. Gould, "Multiple networks and mobilization in the Paris Commune, 1871", American Sociological Review, 1991, 56, pp.716-729.

[22] P. Hedström, "Contagious collectivities: On the spatial diffusion of Swedish trade unions, 1890-1940", American Journal of Sociology, 1994, 99 (5), pp. 1157-1179.

[23] D. Strang, and S.A. Soule, "Diffusion in organizations and social movements: From hybrid corn to poison pills", Annual Review of Sociology, 1998, 24, pp. 265-290.

[24] M. T. Bastos, D. Mercea, and A. Charpentier, "Tents, tweets, and events: The interplay between ongoing protests and social media", Journal of Communication, 2015, 65(2), pp. 320-350.
[25] D. Snow, and R. Benford, "Mobilization Forum: Comment on Oliver and Johnston", Mobilization: An International Quarterly, 2000, 5(1), pp. 55-60.

[26] Papacharissi, Z. Affective publics: Sentiment, Technology, and politics, Oxford University Press, New York, 2015.

[27] A. Sahly, C. Shao, and K.H. Kwon, "Social media for political campaigns: an examination of Trump's and Clinton's frame building and its effect on audience engagement", Social Media+ Society, 2019, 5(2), pp. 1-13.

[28] Z. Papacharissi, and M. de Fatima Oliveira, "Affective news and networked publics: The rhythms of news storytelling on\# Egypt", Journal of Communication, 2012, 62(2), pp. 266282.

[29] S.J. Jackson, and B. Foucault Welles, "\# Ferguson is everywhere: initiators in emerging counterpublic networks", Information, Communication \& Society, 2016, 19(3), pp. 397418.

[30] W.L. Bennett, A. Segerberg, and Y. Yang, "The strength of peripheral networks: Negotiating attention and meaning in complex media ecologies", Journal of Communication, 2018, 68(4), pp. 659-684.

[31] S. Meraz, "Using time series analysis to measure intermedia agenda-setting influence in traditional media and political blog networks". Journalism \& mass communication quarterly, 2011, 88(1), pp. 176-194.

[32] Y. Su and P. Borah, "Who is the agenda setter? Examining the intermedia agenda-setting effect between Twitter and newspapers", Journal of Information Technology \& Politics, 2019, 16(3), pp. 236-249.

[33] C. J. Vargo, L. Guo, and M. A. Amazeen, "The agendasetting power of fake news: A big data analysis of the online media landscape from 2014 to 2016", New media \& Society, 2018, 20(5), pp. 2028-2049.

[34] L. Guo and C. Vargo, 'Fake news' and emerging online media ecosystem: An integrated intermedia agenda-setting analysis of the 2016 USpresidential election", Communication Research, 2020, 47(2), pp. 178-200.

[35] J. Durando. "March for Our Lives could be the biggest single-day protest in D.C.'s history", March 2018, USA Today.

[36] S. Walgrave, and J. Verhulst, "Towards 'new emotional movements'? A comparative exploration into a specific movement type", Social Movement Studies, 2006, 5, pp. 275304.

[37] D.B. Kopel, "The great gun control war of the twentieth century - and its lessons for gun laws today", Fordham Urban Law Journal, 2011, 39, pp. 1572-1616.

[38] W. Vizzard, "The current and future state of gun policy in the United States", Journal of Criminal Law and Criminology, 2015, 104, pp. 879.

[39] S. Messing, C. DeGregorio, B.Hillenbrand, G. King, S. Mahanti, Z. Mukerjee, C. Nayak, N. Persily, B. State, A. Wilkins, 2020, "Facebook Privacy-Protected Full URLs Data Set," https://doi.org/10.7910/DVN/TDOAPG, Harvard Dataverse, V6

[40] S.D. Agarwal, W.L. Bennett, C.N. Johnson, and S. Walker, "A model of crowd enabled organization: Theory and methods for understanding the role of twitter in the occupy protests", International Journal of Communication, 2014, 8, pp. 646-672. 